\title{
Radiografía de la Formación Profesional en España
}

Raquel Vinader-Segura - Universidad Rey Juan Carlos Belén Puebla-Martínez - Universidad Rey Juan Carlos Nuria Navarro-Sierra - Universidad Rey Juan Carlos

Recepción: 16.04.2021 | Aceptado: 27.04.2021

Correspondencia a través de ORCID: Nuria Navarro-Sierra

Citar: Vinader-Segura, R, Puebla-Martínez, B y Navarro-Sierra, N (2021). Radiografía de la Formación Profesional en España. REIDOCREA, 10(20), 1-19.

Resumen: La Formación Profesional se constituye como una pieza clave del sistema educativo en tanto que proporciona una capacitación para el empleo y prepara para la formación a lo largo de la vida. Esta investigación tiene como objetivo realizar una radiografía de la Formación Profesional Reglada en España. Para ello, se ha realizado una exhaustiva revisión documental de fuentes primarias y secundarias a través de las que se muestra una panorámica sobre estos estudios en la actualidad. Los resultados muestran la necesidad de articular acciones que permitan acercar al sistema educativo a la realidad del mundo profesional. Y, por otro lado, se ha descubierto que, cada vez más, los estudios de Formación Profesional se presentan como una alternativa efectiva a los estudios universitarios, dado que suponen una inserción laboral rápida y el egresado tiene a su disposición puestos laborales concretos acordes a su formación académica.

Palabra clave: Formación Profesional

\section{Picture of Vocational Training in Spain}

\begin{abstract}
Vocational training is a key part of the Educational System in that it provides training for employment and prepares for lifelong learning. The aim of this research is to make a radiography of Regulated Vocational Training in Spain. To this end, an exhaustive documentary review of primary and secondary sources has been carried out to provide an overview of these studies at present. The results show the need to articulate actions to bring the educational system closer to the reality of the professional world. And, on the other hand, it has been discovered that, increasingly, Vocational Training studies are presented as an effective alternative to university studies, since they imply a quick labor insertion and the graduate has at his disposal specific job positions in accordance with his academic training.
\end{abstract}

Keyword: Vocational Training

\section{Justificación de la investigación}

La transición de los jóvenes al mercado profesional es, según la OCDE, una de las preocupaciones más importantes de cualquier sociedad (MECD, 2017a). Y en este salto al sector profesional es donde la educación se configura como un elemento clave junto con otros factores como "las condiciones del mercado laboral, el entorno socioeconómico y la demografía" (p.32). La crisis económica mundial vivida desde 2008 ha sido especialmente dañina en nuestro país, donde después de una década parece evidenciarse una recuperación económica cuyos efectos son todavía son tibios en determinados grupos sociales. Especialmente llamativa ha sido la tasa de desempleo entre los jóvenes, con escasa experiencia profesional, llegando a alcanzar un 56,9\% en 2013 según el Instituto Nacional de Estadística (INE). Esto ha obligado a este colectivo a seguir estudiando en un intento de mantenerse ocupado, al tiempo que mejora las competencias que se requieren en el mercado laboral (MECD, 2017b).

Dejando al margen la coyuntura económica, este hecho es relevante si tenemos en cuenta la relación positiva que se establece entre el nivel educativo de las personas y su situación profesional. De este modo, según afirma la OCDE, las personas "que tienen un nivel educativo más alto alcanzan tasas de empleo más elevadas, mientras que las 
personas con un menor nivel de cualificación tienen un riesgo más elevado de estar desempleadas" (MECD, 2017a, p.34). Es, por tanto, obligación de los gobiernos asegurar el derecho a la educación y al empleo, permitiendo a cada ciudadano alcanzar su potencial y adquirir las competencias suficientes para desarrollarse en el mercado del empleo.

Esta preocupación también se encuentra en el ámbito europeo, donde la Unión Europa considera prioritario establecer una estrategia conjunta y coordinada para el empleo "para potenciar una mano de obra cualificada, formada y capaz de adaptarse, así como mercados laborales con capacidad de respuesta al cambio económico, con vistas a lograr los objetivos de pleno empleo y progreso social [...]" (Consejo Europeo, 2015, p.28). Y para ello, es necesario llegar a un alto nivel de educación y formación. En este sentido, en la Estrategia 2020 la Comisión propone alcanzar una serie de objetivos en materia de educación y empleo que, entre otros, pasan por mejorar las tasas de empleo de la población de entre 20 y 64 años, reducir el porcentaje de abandono escolar e incrementar el número de personas con estudios superiores completos. Esta investigación se apoya, por tanto, en la relevancia social y económica de la educación y el empleo.

\section{Objetivos}

A tenor de lo expuesto anteriormente, podemos determinar que el objetivo general de esta investigación es ofrecer una visión panorámica de los estudios de Formación Profesional. Más concretamente, podemos establecer los siguientes objetivos específicos cuya consecución nos permitirá alcanzar el fin de este trabajo:

- Estudiar el origen y finalidad de los estudios de Formación Profesional en el marco del sistema educativo español centrándonos en la configuración actual de estos estudios.

- Establecer un mapa de los estudios de Formación Profesional diferenciando entre centros públicos y privados, analizando la oferta educativa en cada uno de ellos.

\section{Metodología de trabajo}

Teniendo en cuenta los objetivos anteriormente detallados, podemos considerar que la presente investigación tiene un carácter descriptivo en cuanto que se propone el acercamiento y descripción de un objeto de estudio (Del Río y Velázquez, 2005). Para ello, desde un enfoque cuantitativo y cualitativo, se ha seleccionado la técnica del Análisis Documental como la más adecuada para cumplir con nuestros propósitos. Ésta consiste en "una serie de operaciones destinadas a describir y analizar la información documental [...] con el fin de hacerla accesible a todo tipo de usuarios" (Herrero, 1997, p.44). Se trata, por tanto, de una técnica de investigación que consiste en un trabajo de selección y análisis de materiales documentales a partir de los cuales se puede estudiar un fenómeno concreto (Valles, 1999). Según autores como Dulzaides y Molina (2004) sería más apropiado hablar de análisis de información en la medida de que es un proceso de, evaluación, y síntesis de documentos, mientras que el análisis de documentación persigue "representar los documentos de forma unificada sistemática para facilitar su recuperación" (s.p.).

Este trabajo es, por tanto, una investigación secundaria en la medida en la que está basada en la revisión de otras fuentes de información, analizando e interrelacionando los datos más relevantes de las fuentes seleccionadas con la intención de acercarnos al conocimiento preciso de nuestro objeto de estudio. 
Para la aplicación de esta técnica se ha seguido el procedimiento descrito por Valles (1999). En primer lugar, se ha seleccionado el universo documental recurriendo de manera prioritaria a las fuentes primarias oficiales que cumplen con los criterios de autenticidad, credibilidad, representatividad y autoridad. Establecidas las fuentes documentales pertinentes para nuestra investigación, se ha procedido a definir las categorías de estudio relevantes para nuestro objeto de estudio y a continuación se ha realizado el análisis e interpretación de las mismas teniendo en cuenta los propósitos de nuestra investigación.

Las fuentes documentales consultadas (primarias y secundarias) pueden dividirse en dos bloques en función de su diversidad temática:

- Por un lado, todos los estudios relacionados con la Formación Profesional. Se han consultado la información primaria ofrecida por entidades públicas y oficiales como el Ministerio de Educación y Formación Profesional, la Comunidad de Madrid o el Instituto Nacional de Cualificaciones Profesionales. Su catálogo de publicaciones permite consultar estadísticas y anuarios que arrojan luz sobre la cuestión. Del mismo modo, se han analizado otros estudios (fuentes secundarias) que también son relevantes como informes sobre la FP en España de la Fundación la Caixa o la Fundación Antena 3.

- Por otro lado, para seleccionar los datos sobre el empleo en España, la inserción laboral de los titulados de Formación o la FP Dual se ha recurrido a fuentes oficiales (primarias) como las estadísticas e informes publicados por el Observatorio Ocupaciones del Servicio Público de Empleo (SEPE), el Instituto Nacional de Estadística (INE) u organismos como la CEOE. Se completan con informes sobre la materia de entidades privadas como Adecco o Infoempleo, que aportan datos interesantes en la medida en la que monitorizan el estado de la demanda de empleo en nuestro país.

\section{Resultados: los estudios de Formación Profesional}

\section{Antecedentes históricos}

La mayor parte de las investigaciones consultadas arrancan el estudio de la Formación Profesional a partir de la Ley General de Educación (1970). No obstante, otros autores se remontan a la conocida como Ley Moyano aprobada en 1857 para entender los orígenes de este tipo de estudios. No sólo porque supone la formalización del sistema educativo sino porque estuvo vigente hasta 1970 (Brunet y Böcker, 2017; Garrido, 2005). Un hecho que podría interpretarse como desidia por parte de los poderes públicos por abordar la adaptación de las enseñanzas a las nuevas necesidades. En una España culturalmente deprimida, esta ley tiene un efecto modernizador, aunque claramente insuficiente en tanto que las enseñanzas se dirigen a una élite ante una mayoría de ciudadanos con un bajo o nulo nivel de instrucción (Fernández y González, 1975). Se establece así por medio de esta norma dos niveles, elemental y superior, y la obligatoriedad de la enseñanza entre los 6 y los 9 años de edad (Garrido, 2005). En cuanto a la Formación Profesional, queda claramente delimitada al margen de los estudios académicos orientados a la universidad, a los que se les concede un papel más relevante en la vida pública española (Brunet y Bröcker, 2017). Se consagra, de este modo, una vía profesional alternativa, orientada al mercado laboral con cualificaciones profesionales de tipo medio y bajo.

El desarrollo de un sistema de Formación Profesional debe entenderse a partir de las reformas introducidas inicialmente por el Estatuto de Enseñanza Industrial (1924) y el Estatuto de Formación Profesional (1928), a partir de los cuales puede entenderse un 
sistema de capacitación que persigue adaptarse a las demandas del sistema productivo (Fernández y González, 1975). Sin embargo, este tipo de enseñanzas continúan "siendo residuales y casi anecdóticas en España durante la primera mitad del siglo XX" (Bieger et al, 2018, p.17). Un problema que pretende atajarse con de la Ley Orgánica de Formación Profesional Industrial de 1955 que busca relanzar este tipo de estudios a partir de una serie de profundas modificaciones sobre el Estatuto de 1928. Así, la FP se estructura en tres etapas: Preaprendizaje o iniciación profesional, Aprendizaje industrial u Oficialía, y Maestría Industrial con una duración inicial aproximada de 7 años (INCUAL, 2001). Su principal logro no debe situarse únicamente en el incremento de alumnos sino en la implicación directa de los empresarios (Fernández y González, 1975), naciendo así "el compromiso de la clase empresarial con la FP" (Bieger, 2018). Una participación que se concreta tanto en la posibilidad de crear centros de formación interna como en la imposición de tasas para contribuir a la financiación del sistema.

Si bien Fernández y González (1975) resaltan un mayor esfuerzo por impulsar la FP durante la segunda mitad del siglo XX, se aprecian algunos aspectos negativos que condicionan la consolidación de este tipo de estudios como una vía alternativa y relevante a otras enseñanzas. Se evidencia ya en este momento "un menosprecio de estas enseñanzas por parte de la sociedad" (p. 86), que se extiende todavía a nuestros días a pesar de los enormes esfuerzos de los poderes públicos por cambiar esta visión de la Formación Profesional como "un régimen paralelo y marginal".

La Ley General de Educación y Financiación de la Reforma Educativa (LGE) de 1970 se constituye como la primera gran norma educativa de nuestro pasado más reciente "presentando la educación como la auténtica palanca para la movilidad social, la superación de desigualdades y la consecución de una inserción profesional en estratos altos o medios" (Brunet y Bröcker, 2017, p. 93). De este modo, se puede considerar como la primera gran reforma educativa que concibe la educación para todos los ciudadanos con independencia de su estrato social. En este sentido, establece la instrucción obligatoria hasta los 14 años dividiendo el recorrido educativo en dos etapas: ocho cursos de Educación General Básica (EGB), tras los que se podía acceder al Bachillerato Unificado Polivalente (BUP) o la Formación Profesional (Gallego y Rodríguez, 2011). Se persigue acabar así con la FP como una vía menor y alternativa, al integrar este tipo de enseñanzas técnicas y profesionales como una pieza elemental de nuestro sistema educativo (Fernández y González, 1975). Tras los cambios introducidos, la Formación Profesional se articula en tres niveles:

- La FP de Primer Grado (FP1) de dos años de duración y carácter básico para aquellos alumnos que no hubieran completado el título de Graduado Escolar que se otorgaba al superar la EGB.

- La FP de Segundo Grado (FP2) a la que se accedía con el título de Bachiller o tras haber completado la FP1. Durante 3 años se seguían conocimientos complementarios y especializados desde una perspectiva práctica.

- La FP de Tercer Grado (FP3), orientada para graduados universitarios o titulados en FP2, nunca llegó a ponerse en marcha.

Se pretende así capacitar al alumno para el ejercicio de una profesión, pero contribuyendo al mismo tiempo a su formación integral. Gallego y Rodríguez (2011) apuntan, sin embargo, algunos aspectos negativos de esta norma entre los que cabe destacar la excesiva rigidez de los ciclos y modalidades de formación, el adiestramiento frente a la adquisición de competencias, la desvinculación con las necesidades del sector productivo o la falta de colaboración efectiva con el tejido empresarial. De este modo, el resultado de esta reforma fue "una superposición de modelos llenos de contradicciones" (Homs, 2008, p.22) y el desprestigio se extiende rápidamente a pesar 
del incremento de alumnos matriculados. Así, "la FP1 se convirtió en un recipiente de alumnos que habían fracasado en la enseñanza primaria y en el paso previo a la FP2 que inicialmente estaba prevista para bachilleres" (Brunet y Bröcker, 2017, p.94).

La adhesión de España a la Unión Europea en 1985 supone importantes transformaciones que se concretan también en el campo educativo, en tanto que nuestro país adquiere la obligación de "homologar las políticas educativas, sociales, laborales, etc. a las de los distintos países miembros de la Unión" (Gallego y Rodríguez, 2011, p.2058). En 1986, año en que se concreta la integración de nuestro país en la UE, la Ley 1/1986 aprueba la creación del Consejo General de la Formación Profesional, un órgano consultivo adscrito al Ministerio de Trabajo y Asuntos Sociales, y en el que participan asociaciones empresariales y sindicales, con el objetivo de asesorar al Gobierno en todas las cuestiones relacionadas con la Formación Profesional.

Las sucesivas reformativas educativas continuarán el proceso de transformación de estas enseñanzas. Así, en 1990 la Ley Orgánica de Ordenación General del Sistema Educativo (LOGSE) alarga dos años la educación obligatoria, como una manera de evitar una segregación escolar temprana, y establece "las bases de una estructura moderna para la formación profesional" (Homs, 2008, p.24). Pretende de esta manera revalorizar la Formación Profesional "tanto en su imagen social como en la función de puente hacia el trabajo" (Brunet y Bröcker, 2017, p.95), buscando captar una parte del alumnado de la vía universitaria. De este modo, la LOGSE concibe la Formación Profesional como un tipo de enseñanza que no sólo debe preparar a los estudiantes para el ejercicio profesional, sino también para los posibles cambios que se produzcan a lo largo de su vida laboral. Para ello, se combina una formación académica con otra de tipo profesionalizante, organizada en una FP Base, incluida en la Educación Secundaria Obligatoria (ESO) en la que los alumnos puedan adquirir conocimientos, habilidades, destrezas, etc., que le permitan acceder a una FP Específica de Grado Medio mediante el título de ESO, y al Grado Superior, con el título de Bachiller (Gallego y Rodríguez, 2011). Esta FP específica establece unos contenidos organizados en módulos entre los que se incluye la "Formación en Centros de Trabajo" que permite un claro avance en tanto que facilita a los estudiantes una oportunidad de acceso al mercado laboral. La Formación Profesional se constituye así en "una vía respetada de acceso al mercado de trabajo, y, además, ha contribuido a abrir los centros a la realidad del mundo laboral más que cualquier otra medida anterior" (Homs, 2008, p.27). El problema se plantea entonces con aquellos alumnos que no obtuvieran titulación, para los que la LOGSE contempla los denominados Programas de Garantía Social (PGS) que les capacita como profesiones de baja cualificación.

En 2002 el gobierno del Partido Popular aprueba la Ley Orgánica de Calidad de la Educación (LOCE). No obstante, los movimientos políticos posteriores llevaron a que nunca llegara a aplicarse. De este modo, un nuevo gobierno, en este caso socialista, aprueba en 2006 la Ley Orgánica de Educación (LOE) que introduce pequeñas modificaciones en la organización de los estudios de FP en un intento de flexibilizar los procedimientos de acceso a la FP Específica (Grado Medio y Superior) (Bieger et al, 2018; Brunet y Bröcker, 2017; Gallego y Rodríguez, 2011). Posteriormente, la aprobación de la Ley Orgánica 8/2013, de 9 de diciembre, para la Mejora de la Calidad Educativa (LOMCE), también conocida como "Ley Wert", modifica algunos aspectos de la LOE, introduciendo, por ejemplo, la Formación Profesional Básica para sustituir los Programas de Cualificación Profesional Inicial (antes PGS) y dando acceso a los Ciclos de Grado Medio y Superior. 


\section{Marco normativo}

Este apartado tiene como objetivo el repaso de las diferentes normas que son aplicables en el desarrollo de la Formación Profesional en nuestro país. No pretende ser un estudio en detalle de todas las disposiciones legales aprobadas, pero sí que se hará especial mención de aquellas que son más importantes o decisivas en este campo.

En primer lugar, cualquier repaso de la normativa aplicable para el objeto de estudio debe detenerse en la Constitución Española (CE) de 1978, como la norma con mayor rango dentro de nuestro sistema jurídico. Si bien, no establece medidas específicas sobre educación -dispuestas por medidas que analizaremos a continuación-, sí que establece dos principios fundamentales del Estado del Bienestar: el derecho a la educación y el derecho al trabajo. En este sentido, en su artículo 27 establece que todos los ciudadanos tienen derecho a la educación, que se considera obligatoria y gratuita en los niveles básicos, y serán los poderes públicos los encargados de salvaguardar este principio constitucional a través de una "programación general de la enseñanza, con participación efectiva de todos los sectores afectados y la creación de centros docentes". (Constitución Española, 1978, p. 14). Se recoge, de este modo, la consideración de la educación por parte de las Naciones Unidas (1948) como uno de los treinta Derechos Humanos y señala la importancia que tiene en "el pleno desarrollo de la personalidad humana y el fortalecimiento del respeto a los derechos humanos y a las libertades fundamentales" (p. 8). Por su parte, la Unión Europea (UE) en su Carta de los Derechos Fundamentales (2009) amplía este derecho y en su artículo 14 con el "acceso a la formación profesional y permanente", completando así la idea de la educación como elemento básico y señalando la importancia de la formación para el empleo y a lo largo de toda la vida.

Es precisamente en este punto donde se pone en relación con otro derecho fundamental contemplado en nuestro ordenamiento jurídico y de especial relevancia para nuestro objeto de estudio. De esta manera, en el artículo 35 de la CE se reconoce el derecho al trabajo, un elemento especialmente importante en el actual contexto de recuperación tras los estragos de la crisis económica. En este sentido, es importante destacar que los ciudadanos "tienen el deber de trabajar y el derecho al trabajo, a la libre elección de profesión u oficio, a la promoción a través del trabajo y a una remuneración suficiente para satisfacer sus necesidades y las de su familia" (p.16). Así, la Formación Profesional, entendida desde una amplia perspectiva (inicial, para el empleo y la continua para trabajadores) se configura como clave para hacer posible el cumplimiento efectivo de ambos derechos.

\section{Normativa en el ámbito educativo}

Tal y como se ha establecido el reparto de competencias, es el Gobierno Central el que tiene encomendada la labor de homogenizar el sistema educativo a nivel nacional y garantizar "las condiciones de igualdad de todos los españoles en el ejercicio de sus derechos educativos básicos" según lo que se establece en la Constitución Española (SEPE, s.f., p.18). De esta manera, son aplicables las siguientes normas con rango de Ley:

- Ley Orgánica 2/2006, de 3 de mayo, de Educación (LOE) regula el sistema educativo español estableciendo distintos niveles de enseñanza y persiguiendo la mejora necesidad de la calidad de la educación que reciben nuestros jóvenes.

- Fue modificada parcialmente en 2013 por la Ley Orgánica 8/2013, de 9 de diciembre, para la mejora de la calidad educativa (LOMCE). Esta norma 
flexibiliza el acceso al Grado Medio y al Grado Superior, así como establece una nueva modalidad de formación profesional: la FP Dual.

- Ley Orgánica 5/2002, de 19 de junio, de las Cualificaciones y de la Formación Profesional. Tiene como objetivo "la ordenación de un sistema integral de formación profesional, cualificaciones y acreditación, que responda con eficacia y transparencia a las demandas sociales y económicas a través de las diversas modalidades formativas". Supone la creación del Sistema Nacional de Cualificaciones y Formación Profesional.

- Ley 2/2011, de 4 de marzo, de Economía Sostenible. Establece, entre otras cuestiones, la posibilidad de "crear cursos de especialización y una plataforma de educación a distancia para todo el Estado".

- Ley Orgánica 4/2011, de 11 de marzo, complementaria de la Ley de Economía Sostenible, por la que se modifican las Leyes Orgánicas 5/2002, de 19 de junio, de las Cualificaciones y de la Formación Profesional, 2/2006, de 3 de mayo, de Educación, y 6/1985, de 1 de julio, del Poder Judicial. Incorpora en nuestro ordenamiento una reforma de la FP y del Sistema Nacional de Cualificaciones con el objetivo de conseguir una adaptación más rápida a las necesidades de nuestra economía.

No se pueden olvidar otras normas jurídicas con rango de Real Decreto que son fundamentales para la comprensión de la Formación Profesional en nuestro sistema educativo. Cabe destacar las siguientes:

- Real Decreto 375/1999, de 5 de marzo, por el que se crea el Instituto Nacional de las Cualificaciones (BOE del 16 de marzo de 1999). Modificado por el Real Decreto 1326/2002, de 13 de diciembre, (BOE del 14 de diciembre de 2002).

- Real Decreto 1128/2003, de 5 de septiembre, por el que se regula la Catálogo Nacional de Cualificaciones Profesionales. (BOE del 17 de septiembre de 2003). Modificado por el Real Decreto 1416/2005, de 25 de noviembre, (BOE del 3 de diciembre de 2005).

- Real Decreto 1558/2005, de 23 de diciembre, por el que se regulan los requisitos básicos de los Centros integrados de Formación Profesional (BOE del 30 de diciembre de 2005). Corrección de errores (BOE del 24 de enero de 2006).

- Real Decreto 229/2008, de 15 de febrero, por el que se regulan los Centros de Referencia Nacional en el ámbito de la formación profesional (BOE del 25 de febrero de 2008).

- Real Decreto 1224/2009, de 17 de julio, de reconocimiento de las competencias profesionales adquiridas por experiencia laboral.

- Real Decreto 1147/2011, de 29 de julio, por el que se establece la ordenación general de la formación profesional del sistema educativo.

- Real Decreto 1529/2012, de 8 de noviembre, por el que se desarrolla el contrato para la formación y el aprendizaje y se establecen las bases de la formación profesional dual. Reales Decretos por los que se establecen las cualificaciones profesionales

- Real Decreto 127/2014, de 28 de febrero, por el que se regulan aspectos específicos de la Formación Profesional Básica de las enseñanzas de formación profesional del sistema educativo, se aprueban catorce títulos profesionales básicos, se fijan sus currículos básicos y se modifica el Real Decreto 1850/2009, de 4 de diciembre, sobre expedición de títulos académicos y profesionales correspondientes a las enseñanzas establecidas en la Ley Orgánica 2/2006, de 3 de mayo, de Educación.

- Real Decreto 1058/2015, de 20 de noviembre, por el que se regulan las características generales de las pruebas de la evaluación final de Educación Primaria establecida en la Ley Orgánica 2/2006, de 3 de mayo, de Educación. 


\section{La Formación Profesional en el sistema educativo español}

La Ley Orgánica de las Cualificaciones y de la Formación profesional (LOCFP) establece en 2002 la "ordenación de un sistema integral de formación profesional" que tiene como objetivo la respuesta a las demandas formativas del sector productivo, favoreciendo la formación a lo largo de toda la vida en función de las distintas expectativas y situaciones personales y profesionales. En este sentido, la Formación Profesional se concibe no sólo como la capacitación para el empleo y el desempeño profesional, sino también para el desarrollo de la vida social, económica y cultural de los ciudadanos. Comprende, según la Ley, acciones formativas que incluyen "enseñanzas propias de la formación profesional inicial, las acciones de inserción y reinserción laboral de los trabajadores, así como las orientadas a la formación continua en las empresas". De este modo, la oferta de Formación Profesional se constituye en tres subsistemas: reglada, ocupacional y continua:

- La FP reglada, también conocida como inicial, depende del Ministerio de Educación y Formación Profesional y de las Consejerías de educación de las Comunidades Autónomas. Forma parte del sistema educativo y sus acciones formativas buscan capacitar a los estudiantes para el desempeño de una profesión y conducen a la obtención de un título oficial de FP Básica, Grado Medio o Superior según los casos.

- La Formación Ocupacional (FPO) está gestionada por el Ministerio de Trabajo, Migraciones y Seguridad Social a través del Servicio Público de Empleo Estatal (SEPE, 2015). Tiene como fin "impulsar y extender entre las empresas y los trabajadores ocupados y desempleados una formación que mejore la empleabilidad y el desarrollo profesional y personal de los trabajadores" (p.46) a través de cursos en modalidad presencial, tele-formación o mixta.

- La Formación Continua ofrece programas de formación para trabajadores en activo a través de la Fundación Estatal para la formación en el empleo (FUNDAE) (s.f.), antes la Fundación Tripartita, con la intención de "responder a las necesidades del mercado de trabajo y contribuir al desarrollo de una economía basada en el conocimiento".

Desde 2007 la formación para desempleados y para profesionales en activo están unificadas bajo la dominación de Formación Profesional para el Empleo, eliminando así las barreras entre los trabajadores desempleados y en activo, a pesar de que las acciones ofertadas puedan ser específicas para un colectivo u otro (Sotés-Elizalde, 2009). Al mismo tiempo, este tipo capacitaciones permiten la obtención de certificados de profesionalidad que tiene como objetivo mejorar la transparencia del sistema laboral y facilitar la movilidad de trabajadores en la Unión Europea (SEPE, s.f.). De este modo, este tipo de títulos permiten a los profesionales acreditar sus competencias adquiridas mediante estas acciones formativas y/o en el ejercicio de su profesión.

La FP Reglada es, según Infoempleo (2017), "una de las alternativas con mejores salidas profesionales en España" (p.106). En la actualidad se ofrecen más de 150 títulos que se organizan en áreas de conocimiento denominadas como 26 familias profesionales que pretenden responder a las necesidades formativas del sector profesional. 


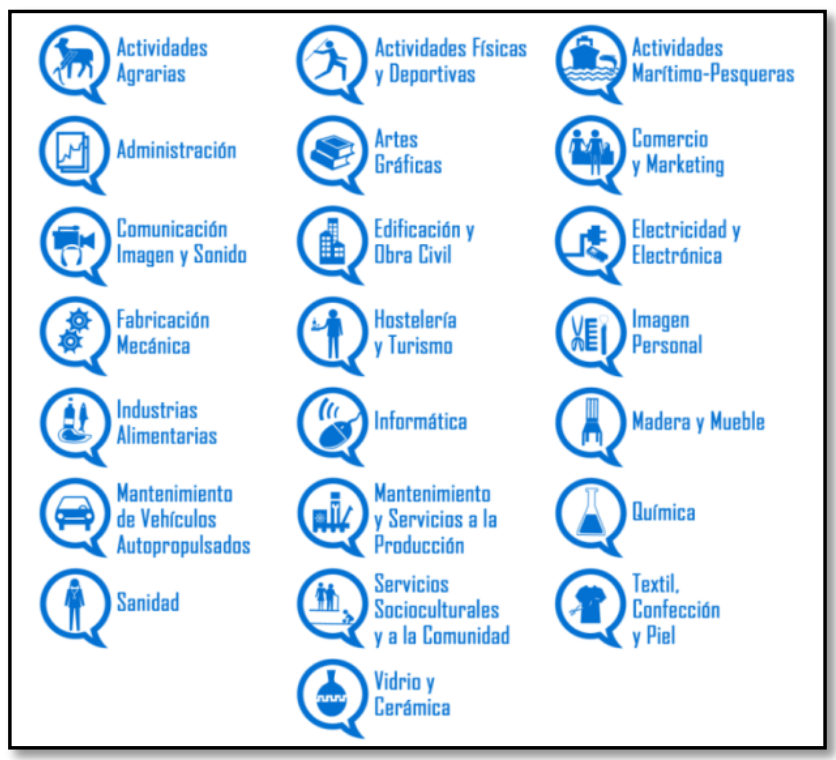

Figura 1: Estudios de FP reglada por Familias Profesionales (Todofp.es)

La FP, parte del sistema educativo, está diseñada como un conjunto de ciclos formativos con una organización modular y basada en contenidos teórico-prácticos de duración variable en función del tipo de estudios y acordes al Catálogo Nacional de Cualificaciones Profesionales. Dentro de cada familia profesional, se ofertan distintos niveles de enseñanza (Ministerio de Educación y Formación Profesional, 2017).

En primer lugar, la FP Básica, de carácter obligatorio y gratuito, dirigida a estudiantes que no han completado sus estudios de ESO y quieren continuar en enseñanzas orientadas a la inserción laboral. Para acceder es necesario tener entre 15 y 17 años, haber cursado $3^{\circ}$ de ESO -excepcionalmente $2^{\circ}$ ESO) y tener la recomendación del equipo docente de la ESO y el consentimiento de los tutores legales. En estos momentos se puede acceder a 34 títulos de 19 Familias profesionales distintas. Todos ellos siguen el mismo esquema: estudios de dos años de duración con módulos asociados a bloques comunes (Comunicación y Sociedad, y Ciencias Aplicadas), a unidades de competencia del Catálogo Nacional de Cualificaciones Profesionales y el módulo de "Formación en Centros de trabajo". Este tipo de formación se corresponde al nivel 1 de cualificación profesional del INCUAL y permite la obtención de un título de Técnico Profesional Básico.

Por otro lado, los Ciclos Formativos de Grado Medio (CFGM) forman parte de la Formación Profesional Específica y se integran en las enseñanzas secundarias postobligatorias. Está orientada para alumnos que buscan una capacitación para una determinada profesión. Los requisitos de acceso son tener el título de ESO/FP Básica, haber superado el curso de acceso o la prueba de acceso a grado medio o a la universidad para mayores de 25 años. En este sentido, hay disponibles en estos momentos más de 60 títulos de 25 familias distintas que se corresponden al perfil profesional 2 definido por el INCUAL. La duración de estos ciclos es de 2.000 horas divididos en dos cursos académicos y la obligación para el estudiante de realizar el módulo de "Formación en Centros de Trabajo". Su superación habilita al estudiante como un Técnico Profesional.

Por último, los Ciclos Formativos de Grado Superior (CFGS) forma parte de la educación superior con un carácter práctico. De la misma manera que los anteriores están 
diseñados para ser cursados durante dos años académicos, reservando el último trimestre del segundo año para las prácticas profesionales de la FCT. Para poder realizar este tipo de estudios es necesario acreditar con carácter general un título de Bachiller (o superior), haber superado la prueba de acceso específica, la de acceso a la universidad para mayores de 25 años o haber superado el curso de acceso. La oferta actual es bastante amplia con más de 90 títulos de 25 áreas de especialización. Este tipo de formación se corresponde con perfil profesional 3 definido por el INCUAL. Al final de todos los módulos, el estudiante obtendrá un título oficial de Técnico Superior que le permitirá acceder al mercado laboral.

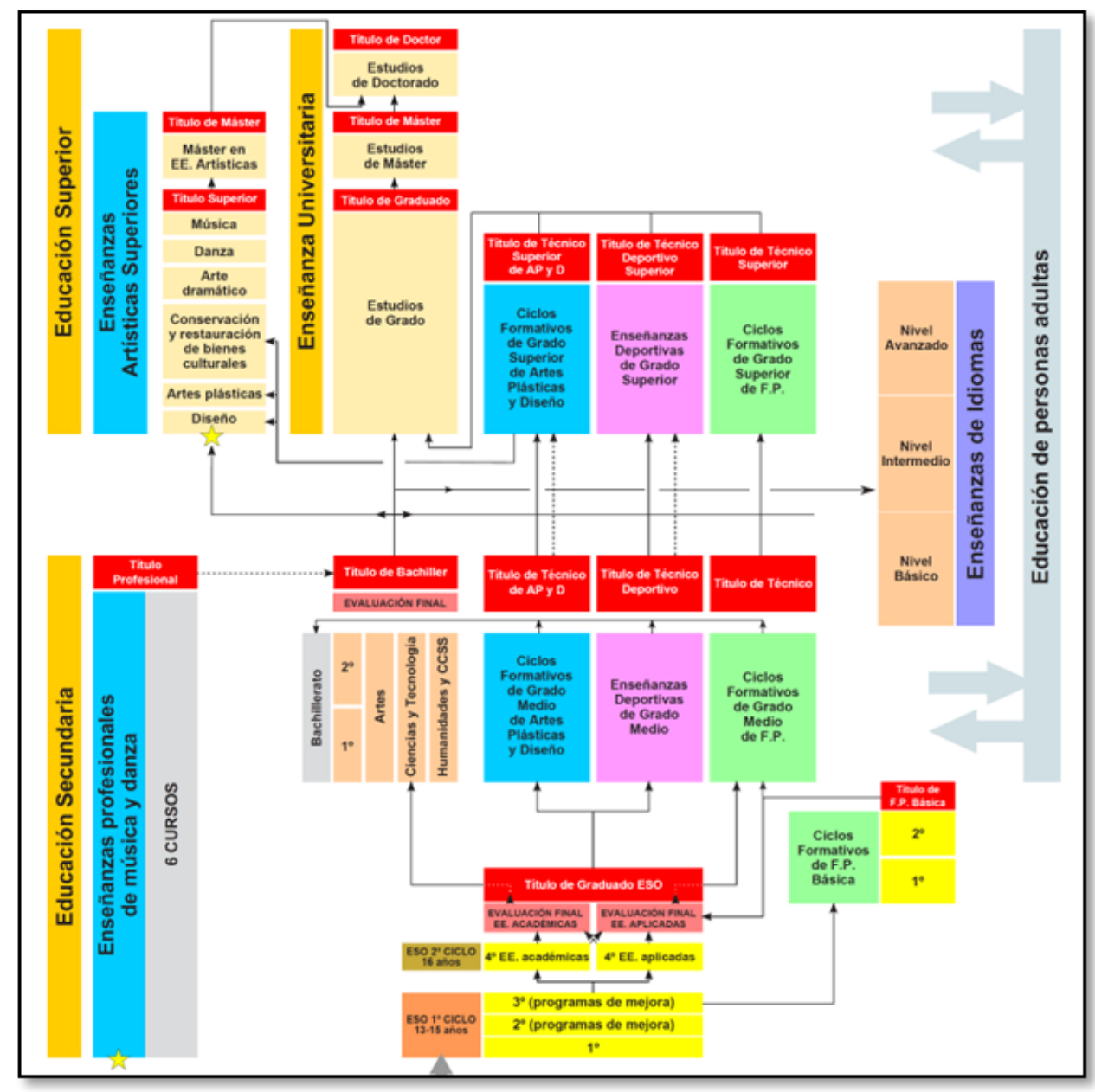

Figura 2: Esquema del sistema educativo: enseñanza secundaria y superior (Ministerio de Educación, 2019)

Una vez finalizado un ciclo de Grado Superior (CFGS), como puede observarse en la figura 2, el sistema educativo permite al estudiante la progresión hacia otras enseñanzas superiores ya sean universitarias. De este modo, a partir de un proceso de selección con la nota media de su expediente, el alumno tiene la posibilidad de elegir aquellos estudios que mejor se adecúen a sus expectativas laborales y profesionales, así como a sus intereses en cada momento. Una vía cada vez más utilizada por jóvenes interesados en adquirir nuevos conocimientos y competencias.

\section{Radiografía de la Formación Profesional Reglada en España}

Durante el curso 2017-2018 el conjunto de las administraciones públicas realizó un gasto en educación estimado en 51.275,9 millones de euros incluidos los gastos financieros (Ministerio de Educación e Formación Profesional, 2018). Un gasto por 
alumno de 7.019 euros por alumno, muy por debajo de otros países europeos como Luxemburgo (17.683€), Austria (11.083€) o Suecia (10.117€). El grueso de la inversión estimada para ese curso fue consignado a la partida de Educación Infantil, Primaria y Especial (34,5\%) frente a ESO, Bachillerato y FP (29,9\%) o Educación Universitaria $(19,9 \%)$ entre otras categorías, siendo los gastos en personal $(67,4 \%)$ la partida más importante. Lamentablemente el Ministerio no ofrece datos desagregados para conocer la inversión realizada de manera específica en Formación Profesional, objeto de nuestro estudio. A continuación, se analizan los principales indicadores de este tipo de enseñanzas a partir de tres ejes principales: el alumnado, el profesorado y los centros educativos.

\section{Alumnado}

Según el avance de datos que ofrece el Ministerio de Educación y FP (2018), el número de alumnos matriculados en enseñanzas no universitarias para el curso 2017-2018 era de 8.158.605, a los que habría que sumar los 824.408 del Régimen Especial (enseñanzas artísticas). Como puede verse en el gráfico 1, durante el curso analizado los estudiantes matriculados en cualquiera de las enseñanzas que componen la Formación Profesional ascendieron a 804.829 alumnos, es decir, un 9,9\% de los estudiantes del Régimen General.

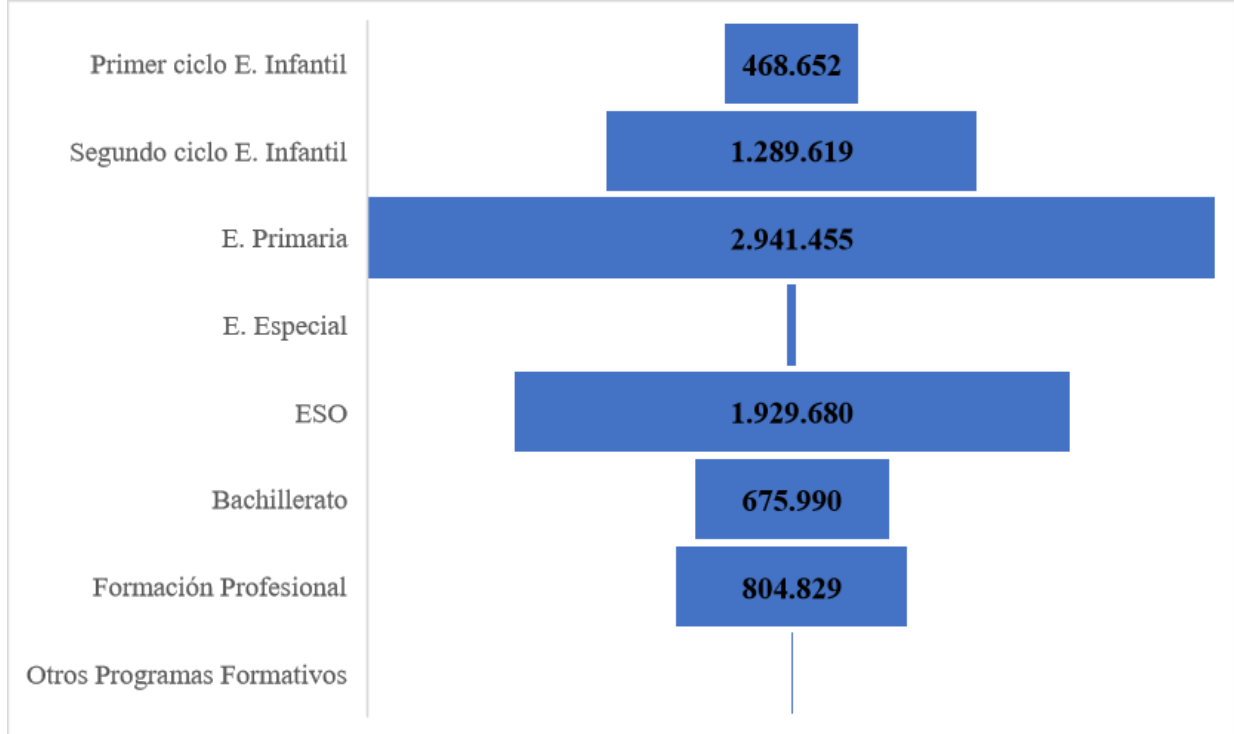

Gráfico 1: Distribución del alumnado por enseñanzas en el Régimen General no universitarias (Ministerio de Educación, 2019)

Al mismo tiempo, si tenemos en cuenta los diferentes niveles dentro de los estudios de FP, podemos observar la distribución más o menos equilibrada entre los alumnos de Grado Medio (314.434) y de Grado Superior (342.709). Por tanto, en el curso 2017-2018 había más estudiantes matriculados en los Ciclos Formativos de Grado Superior que en Grado medio, aunque la diferencia no es significativa. A esto hay que sumar a los estudiantes de FP a distancia (75.500) y la FP Básica (72.186), que son cuantitativamente menos importantes. Estas cifras, representativas en sí mismas, cobran especial importancia en la medida en la que se contextualizan y se constata una evolución positiva en la última década.

De este modo, según se muestra en el siguiente gráfico, el número de estudiantes que cursan cualquiera de las enseñanzas de la FP reglada lleva una tendencia ascendente en el período analizado (2007-2018). De esta manera, se observa un crecimiento del $174 \%$ en la última década, en la que se ha pasado de 462.492 estudiantes de FP en el 
curso 2007-2008 a 804.829 que se calculan para el curso 2017-2018. Junto con la FP de grado medio y superior, la implantación de la FP básica y las enseñanzas a distancia colaboran en este incremento de estudiantes. Se constata de este modo un avance importante en número de alumnos de Formación Profesional, lo que podría llevarnos a concluir que este tipo de estudios han mejorado su imagen social captando cada vez más estudiantes que buscan una formación específica que les permita una mejor inserción laboral en el mercado profesional.

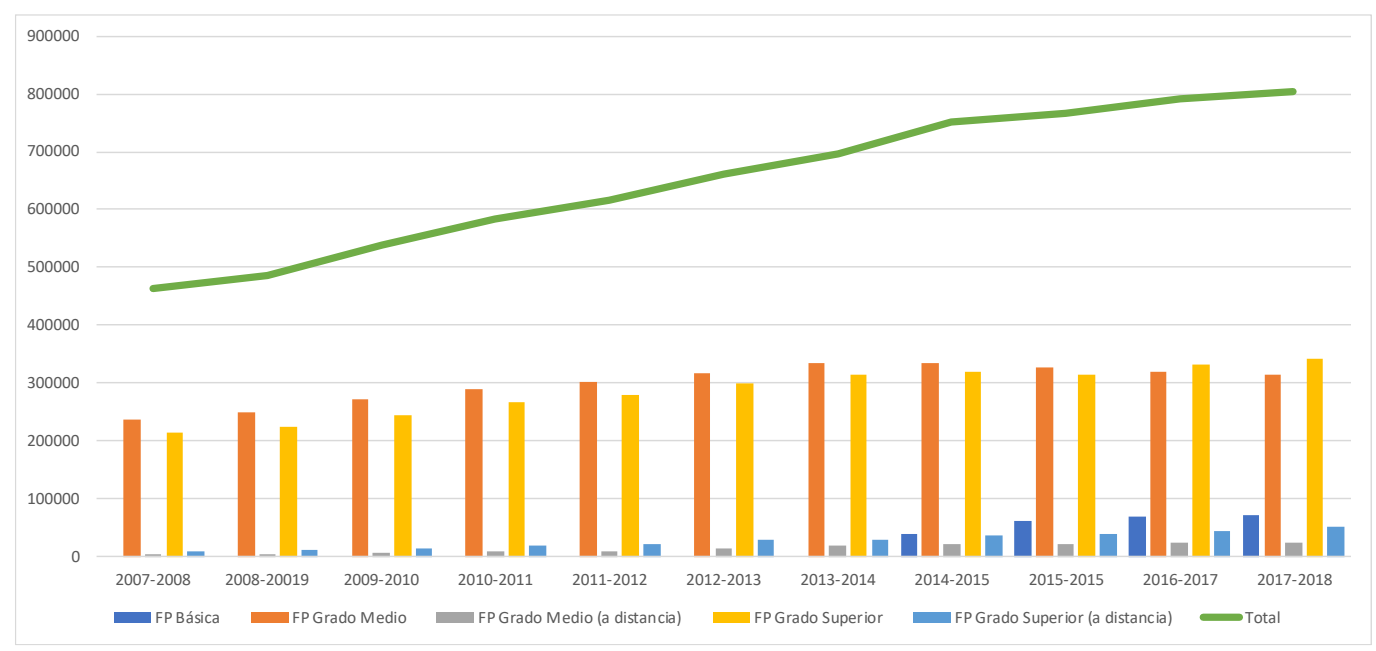

Gráfico 2: Evolución del alumnado de Formación Profesional en el período 2007-2018 (Ministerio de Educación, 2019)

No obstante, este incremento en el número de matriculados se distribuye de manera desigual territorialmente. Así, las mayores tasas de crecimiento se localizan en Melilla (27\%), Ceuta (26,2\%), La Rioja (19,1\%) o la Comunidad de Madrid (19\%). Nos encontramos entonces con dos los dos territorios, Ceuta y Melilla, que menos alumnos matriculados pero que han experimentado tasas de incremento importantes. Por su parte, Andalucía (17,6\%), Cataluña (16,3\%), Comunidad Valenciana $(11,9 \%)$ y Madrid $(11,8 \%)$ son las comunidades autónomas con mayor número de matriculados en enseñanzas no universitarias y también en FP.

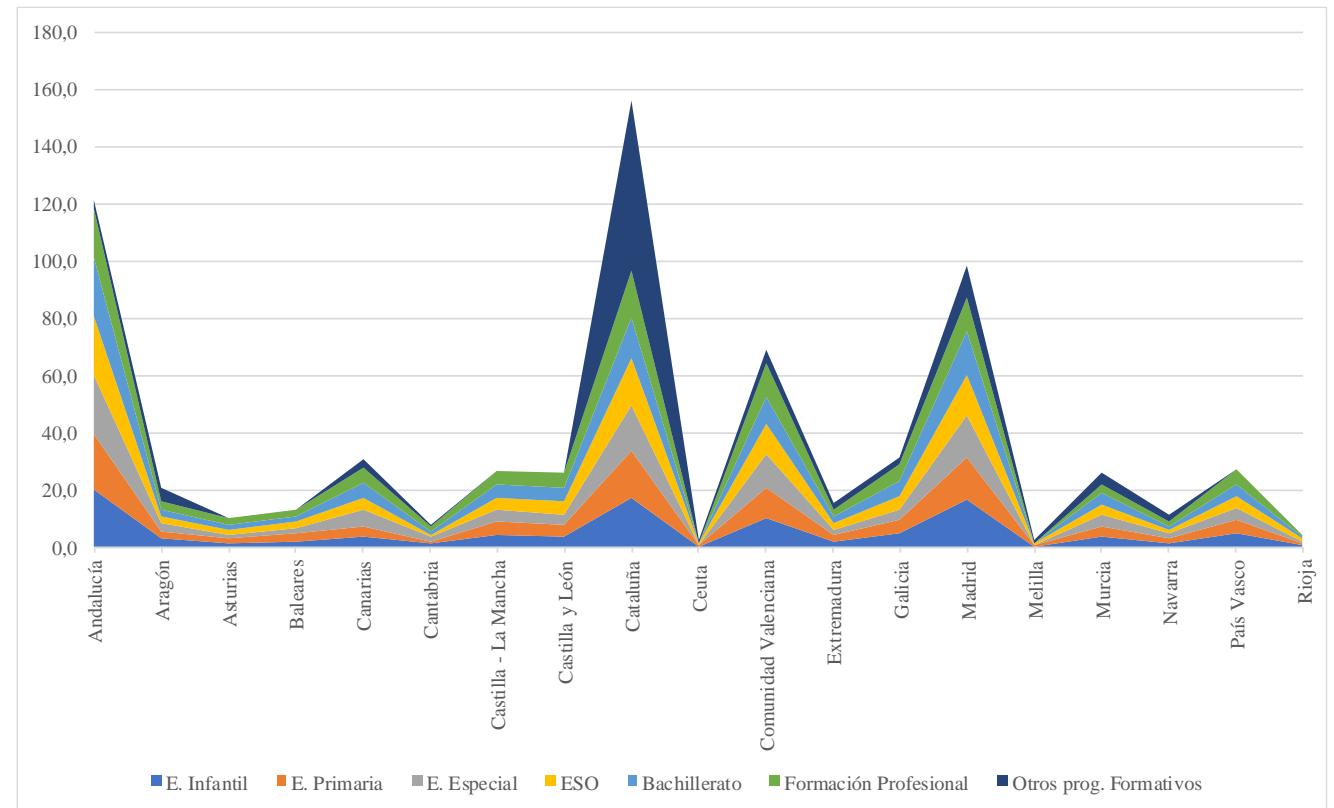

Gráfico 3: Distribución de alumnos matriculados por enseñanza y Comunidad Autónoma (Ministerio de Educación, 2019) 
El perfil del alumno de Formación Profesional difiere si tomamos consideración nivel de enseñanza. Así, se evidencia una proporción desigual entre el porcentaje de hombres $(56 \%)$ y mujeres (44\%). Un perfil ligeramente más masculinizado si tenemos en cuenta la media de los estudiantes de las enseñanzas no universitarias del Régimen General: $51,7 \%$ y $48,3 \%$ respectivamente. Al mismo tiempo, si estudiamos esta variable en función del tipo de estudios de FP, nos encontramos con datos opuestos. Así, mientras en la FP Básica se observa que el $70,8 \%$ de los estudiantes son hombres, este reparto por género da un vuelco en el caso de la FP a distancia (Grado Medio y Superior) con un $60 \%$ de mujeres matriculadas.

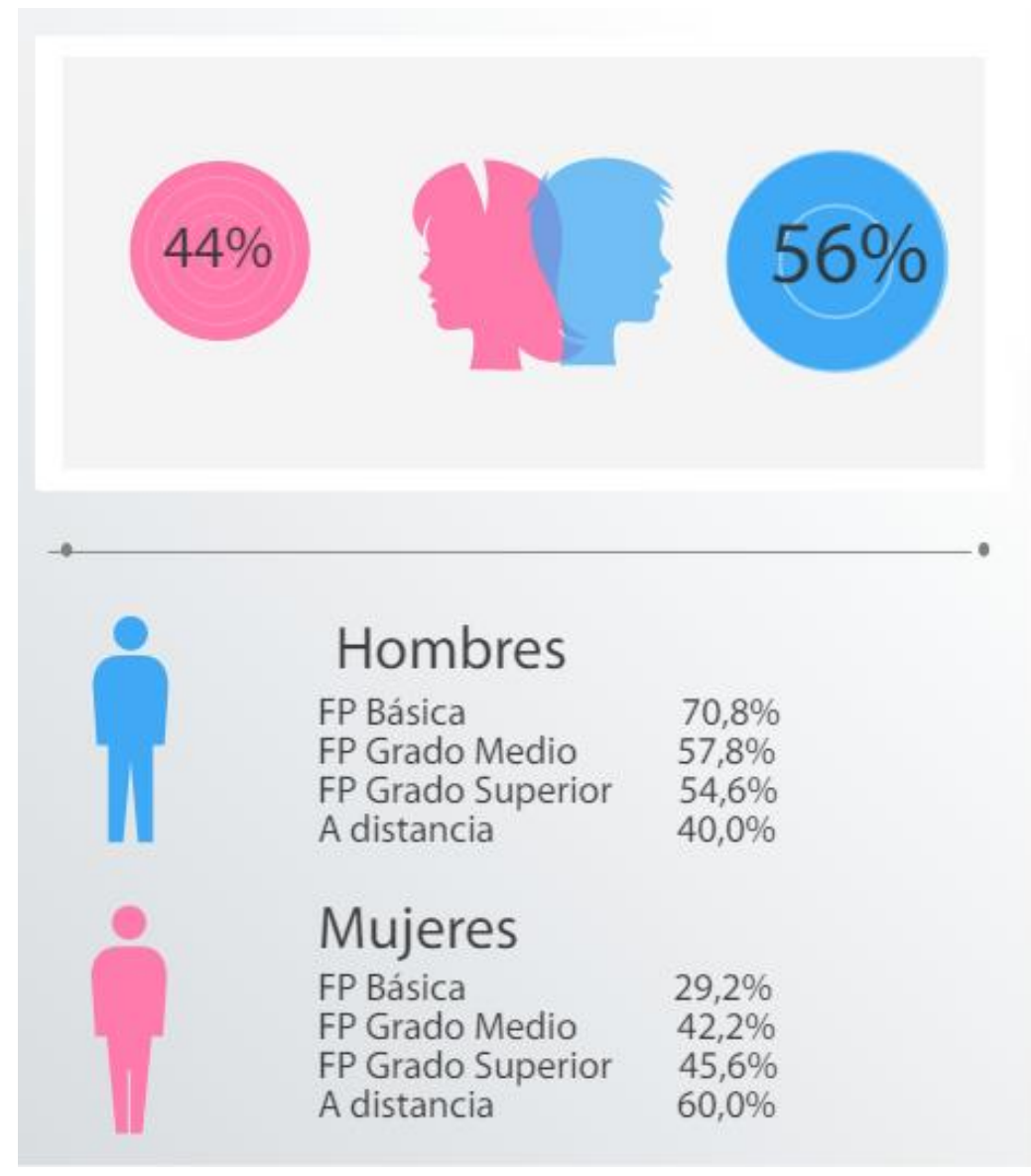

Figura 3: Perfil del alumnado de FP durante el curso 2017-2018 (Ministerio de Educación, 2019)

La cuestión del género es así mismo relevante si consideramos el contenido de los estudios. De esta manera, no todos los títulos de FP gozan de la misma popularidad o aceptación entre chicos y chicas. De este modo, la tabla 1 recoge la distribución de los alumnos en función de los estudios en los que se encuentran matriculados. Los títulos más demandados son "Sanidad" con 118.325 estudiantes en el curso 2016-2017, seguido de "Administración y gestión" (116.408) e "Informática y comunicaciones" (86.531).

No obstante, si desagregamos estos datos por género, nos encontramos un rendimiento desigual por especialidad. Así, se constata estudios con un marcado perfil masculino o femenino en función de la demanda. Frente a "Informática y Comunicaciones", "Electricidad y Electrónica" o "Mantenimiento de Vehículos Autopropulsados" que son las categorías en las que prevalece un estudiante varón, nos encontramos con títulos como "Sanidad", "Servicios Socioculturales y a la Comunidad" o "Imagen Personal" en los que se concentra una mayoría de mujeres. 
Tabla 1: Distribución de los alumnos matriculados por título y género (MEyFP, 2019)

\begin{tabular}{|c|c|c|c|c|c|c|}
\hline & \multicolumn{2}{|c|}{ FP Básica } & \multicolumn{2}{|c|}{ FP Grado Medio } & \multicolumn{2}{|c|}{ FP Grado Superior } \\
\hline & Hombres & Mujeres & Hombres & Mujeres & Hombres & Mujeres \\
\hline Agraria & 3.290 & 809 & 6.164 & 1.065 & 5.180 & 1.235 \\
\hline Act. Físicas y deportivas & 0 & 0 & 7.734 & 2.003 & 16.799 & 4.243 \\
\hline Acr. Marítimo-Pesqueras & 28 & 1 & 1.526 & 113 & 1.604 & 176 \\
\hline Administración y gestión & 3.122 & 6.288 & 19.938 & 30.598 & 20.572 & 35.530 \\
\hline Artes Gráficas & 285 & 208 & 2.163 & 1.179 & 1.081 & 970 \\
\hline Comercio y Marketing & 1.833 & 2.129 & 6.992 & 9.131 & 12.080 & 11.229 \\
\hline Edificación y obra civil & 582 & 55 & 575 & 145 & 2.972 & 1.334 \\
\hline Electricidad y electrónica & 9.312 & 328 & 26.205 & 776 & 22.325 & 1.143 \\
\hline Fabricación mecánica & 4.742 & 123 & 11.246 & 343 & 8.286 & 6 \\
\hline Hostelería y Turismo & 3.893 & 2.533 & 12.304 & 7.492 & 9.642 & 12.397 \\
\hline Imagen Personal & 898 & 4.962 & 1.648 & 17.093 & 418 & 6.877 \\
\hline Imagen y Sonido & 0 & 0 & 2.218 & 691 & 10.178 & 4.954 \\
\hline Industrias Alimentarias & 199 & 147 & 2.141 & 2.565 & 1.194 & 1.054 \\
\hline Informática y Comunicaciones & 9.024 & 1.956 & 28.584 & 2.494 & 39.252 & 5.221 \\
\hline Mad., Mueble y Corcho & 1.549 & 143 & 2.322 & 180 & 682 & 186 \\
\hline Instalación y Mantenimiento & 368 & 13 & 11.360 & 249 & 10.456 & 1.752 \\
\hline Mantenim. Vehículos Autopropulsados & 6.825 & 135 & 26.841 & 670 & 10.596 & 308 \\
\hline Química & 0 & 0 & 1.275 & 1.631 & 3.628 & 3.661 \\
\hline Sanidad & 0 & 0 & 19.959 & 52.160 & 12.163 & 34.043 \\
\hline Serv. Socioculturales y a la Comunidad & 51 & 184 & 3.015 & 18.332 & 7.210 & 49.626 \\
\hline Textil, Confección y Piel & 203 & 241 & 226 & 1.048 & 210 & 1.311 \\
\hline Vidrio y Cerámica & 47 & 22 & 59 & 13 & 24 & 21 \\
\hline Artesanias & 0 & 0 & 0 & 0 & 65 & 50 \\
\hline Energía y Agua & 0 & 0 & 0 & 0 & 2.024 & 220 \\
\hline Seguridad y Medio Ambiente & 0 & 0 & 224 & 26 & 633 & 336 \\
\hline Industrias Extractivas & 0 & 0 & 161 & 6 & 0 & 0 \\
\hline Sin distribuir & 0 & 0 & 35 & 2 & & 0 \\
\hline
\end{tabular}

La presencia de estudiantes de origen extranjero es otro factor de análisis relevante para conocer el perfil de los alumnos matriculados en estas enseñanzas. Así, desde el curso 2007-2008 el número de estudiantes no nacionales se ha duplicado y, según las cifras oficiales, ha pasado de 35.272 a 63.213 alumnos en 2017-2018, repartiéndose en Básica (17,4\%), Grado Medio (46,2\%) y Grado Superior (36,4\%). Cataluña, Islas Baleares, La Rioja, Murcia y Aragón son las comunidades en las que hay mayor presencia de este colectivo en toda la oferta de educación no universitaria. En cuanto a la procedencia del alumnado destacan África (30,5\%), la Unión Europea (29\%) y América (25\%) repartidos de manera desigual por la geografía española.

Por otro lado, en cuanto a la titularidad de los centros en los que está matriculado el estudiante de FP sobresalen aquellos alumnos que están matriculados en centros de titularidad pública $(72,6 \%)$ frente a centros privados $(9,2 \%)$ o concertados $(18,2 \%)$ cifras algo superiores a la media de las enseñanzas del Régimen General. El importante papel que juegan los centros públicos es evidente en todos los niveles del sistema educativo como puede verse en el siguiente gráfico. Los centros concertados, si bien están presentes en todos los niveles, no adquieren niveles tan representativos. Y, por su parte, los centros privados, es decir aquellos en los que no hay ningún tipo de concierto o subvención pública en el desarrollo de la función educativa, adquieren más importancia en el primer ciclo de educación infantil en el que la oferta pública se muestra en muchas ocasiones como insuficiente en un nivel que no es obligatorio para las familias. 


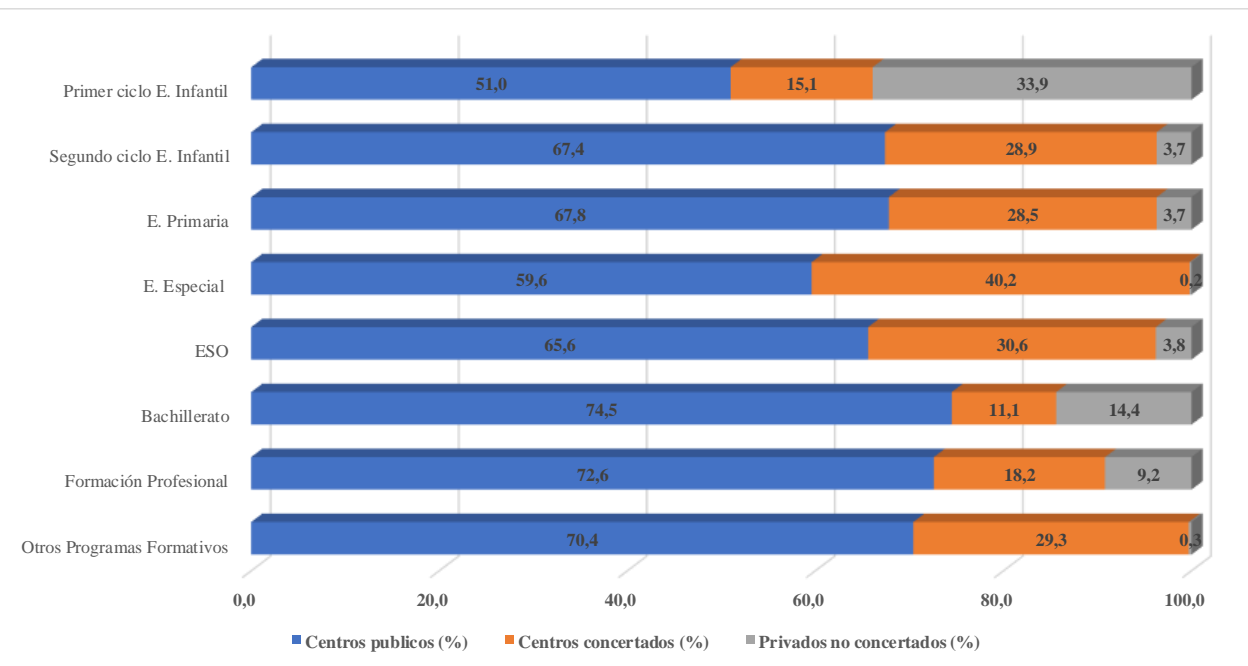

Gráfico 4: Distribución de alumnos matriculados en el régimen General por titularidad de centro (MEyFP, 2018)

\section{Profesorado}

Las estadísticas ofrecidas por el Ministerio de Educación y Formación Profesional (2019) nos ayudan a describir y analizar el profesorado que desempeña su actividad docente en el sistema educativo español, con especial importancia en el de Formación Profesional. Este estudio sólo considera aquellos profesionales que prestan su actividad docente durante el horario escolar y no considera, por tanto, aquellos que intervienen de manera exclusiva en actividades extraescolares y/o complementarias. Es decir, que las cifras que se explican a continuación deberían verse incrementadas con este colectivo para hacernos una idea del volumen total de docentes. No obstante, esto no supone un problema para nuestro objeto de análisis caracterizado por un alumnado más adulto que no requiere a priori de este tipo de servicios.

Según fuentes oficiales (MEyFP, 2019), durante el curso 2016-2017, últimos datos cerrados y consolidados, había registrados 688.466 profesores y se preveía que esta cantidad se vería incrementada hasta los 701.373 en el siguiente curso académico. Esto es, un incremento de casi 13.000 docentes. La mayor parte del profesorado $(70,84 \%)$ se concentran en la enseñanza pública siendo el cuerpo de maestros el más significativo con 244.842 docentes en el curso 2016-2017. En comparación, hay que destacar que los profesores dedicados a la Formación Profesional son el colectivo menos representativo con respecto al volumen total de profesores de las enseñanzas del Régimen General. Así, suponen 26.431 profesionales, es decir, un 5,4\% si tomamos como referencia únicamente los profesores de centros de titularidad pública y un $3,8 \%$ sobre el total del profesorado. En cuanto a los docentes de centros concertados y privados, unos 200.740 (29,1\%) en el curso 2016-2017, no se ofrecen los datos organizados en categorías o dedicaciones.

El perfil medio del docente es claramente femenino $(71,9 \%)$ aunque en el caso de la Formación Profesional se observa cómo se altera la tendencia y los profesores son más numerosos $(55,7 \%)$ frente a las profesoras $(44,3 \%)$. En cuanto a la edad, la mayor parte de los profesionales se concentran en los rangos de edad que oscilan entre los 30 y los 59 años, siendo aquellos que se sitúan entre los 40 y 49 años, aunque por poco, los más importantes $(30,7 \%)$. El análisis varía si cruzamos estos datos con variables como la titularidad del centro en la que imparten docencia o el tipo de enseñanza. Así, los profesores más jóvenes (menos de 30 y de 40) se concentran en los centros de titularidad concertada y privada, y los profesores dedicados a la FP muestran un perfil más adulto. 
Por último, para acabar con este apartado, es interesante analizar la ratio alumnoprofesor y su comparación a nivel nacional e internacional. De este modo, en España durante el curso 2016-2017, y teniendo en cuenta los datos publicados por el Ministerio de Educación y FP (2019), cada profesor a tiempo completo tuvo una media de 12,5 estudiantes a su cargo. Siendo la Comunidad de Madrid (14) y Melilla $(13,9)$ las comunidades con mayores valores y Galicia $(10,4)$ o Extremadura $(10,6)$ los territorios con menor ratio. Son datos que se sitúan ligeramente por encima de la media europea pero muy por encima de países como Lituania $(8,1)$, Grecia $(8,8)$ o Malta $(9,4)$.

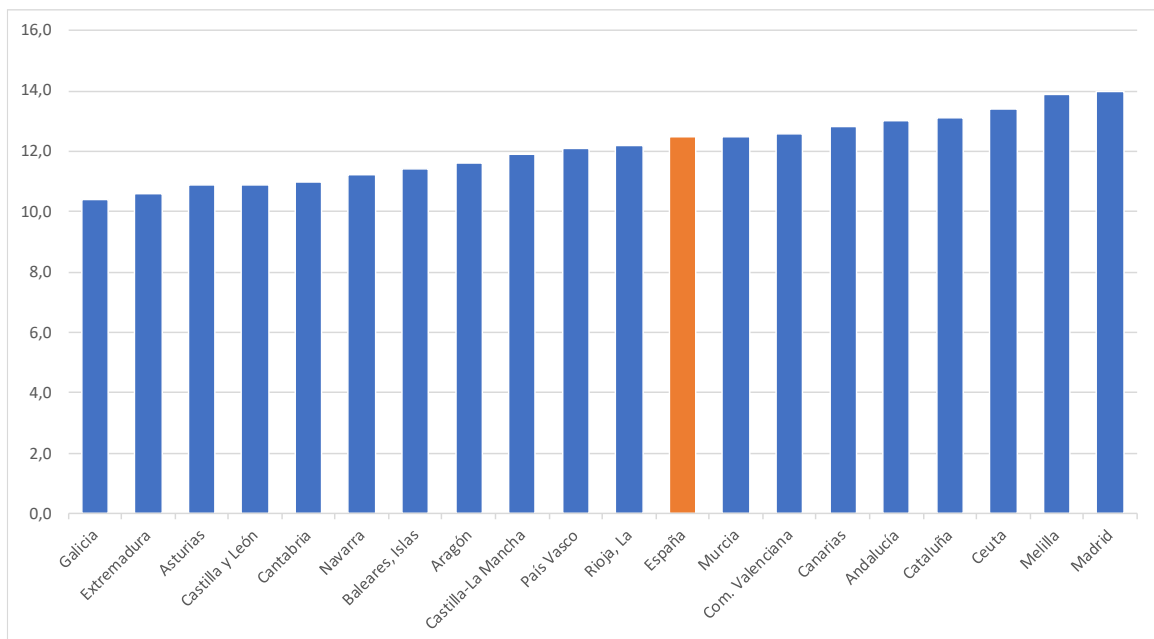

Gráfico 5: Ratio de profesor-alumnos por Comunidad Autónoma durante el curso 2016-2017 (Ministerio de Educación, 2019)

A pesar de que los datos oficiales no se ofrezcan con más detalle, señalar que los profesores se distribuyen geográficamente de manera desigual por la geografía española en función de la demanda. De este modo, Andalucía (152.037), Cataluña (139.767) y Madrid (120.106) son las comunidades autónomas donde se sitúan la mayor parte de los docentes de centros españoles de los cuales más de una tercera parte corresponden a profesores dedicados a la Formación Profesional: un 38,3\% en el caso de Andalucía, 35,65\% en Cataluña y un 39,5 en Madrid.

\section{Centros educativos}

El Ministerio de Educación y FP (2019) entiende como centro educativo como aquel "creado o autorizado por las Administraciones Educativas que imparte enseñanzas del sistema educativo en el curso de referencia" (p.17), ya sean de titularidad pública o privada. Es decir, que el promotor de la actividad educativa sea una entidad pública (Ministerio, Comunidad Autónoma o Ayuntamiento, entre otras) o una institución privada, reciba o no fondos públicos para su gestión. Durante el curso 2018-2019 las previsiones muestran una oferta de 28.531 centros educativos dentro del Régimen General de enseñanzas no universitarias; una cifra algo superior a los 28.211 del curso 2016-2017. Los datos constatan de nuevo la importancia de los centros de titularidad pública, que prevalecen sobre los concertados y privados. Así, se calcula que la escuela pública suponga en el curso 2018-2019 el 66,9\% del total de centros frente a los 9.419 $(33 \%)$ de los centros concertados y privados.

La distribución de centros por Comunidades Autónomas es desigual y se ajusta la densidad de población y la demanda por parte de los estudiantes. Como puede verse en la siguiente figura, y atendiendo a los datos del curso 2016-2017, en nuestro país el mayor número de centros se sitúan en Andalucía, Cataluña y la Comunidad de Madrid. Estas tres autonomías concentran el $49 \%$ de la oferta. 


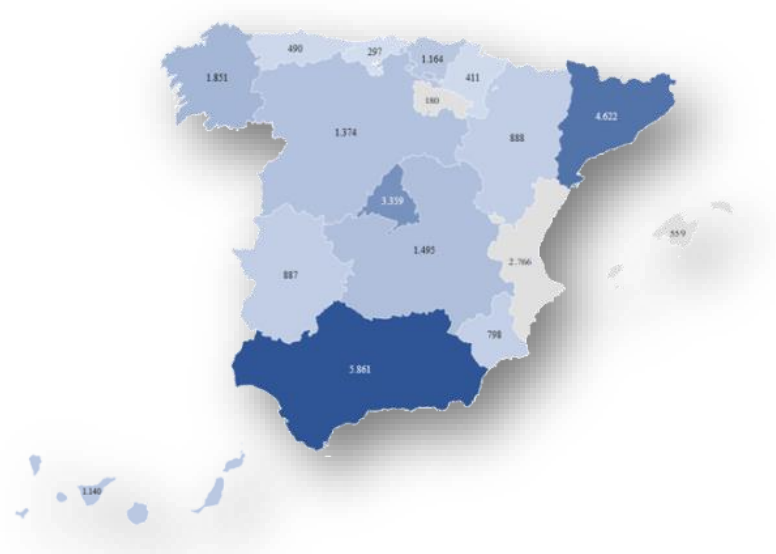

Figura 4. Distribución de centros educativos por Comunidades Autónomas. Curso 2016-2017 (Ministerio Educación, 2019)

Al mismo tiempo, hay que destacar que la proporción de centros públicos frente a concertados y privados no se mantiene en cada territorio. De esta manera, partiendo de una tendencia generalizada al predominio de centros públicos, ésta es más acusada en comunidades como Extremadura o Asturias con una prevalencia superior al $80 \%$. En el polo opuesto sobresale sobre el resto la Comunidad de Madrid en la que los centros se reparten al $50 \%$ entre los de titularidad pública y los privados y concertados.

Estos datos expuestos nos permiten tener una visión general sobre el mapa de la oferta educativa en España. Es pertinente para el análisis de nuestro objeto de estudio conocer con más detalle el panorama de la Formación Profesional. En este sentido, es necesario aclarar que los datos que publica el Ministerio de Educación y FP (2019) nos muestran la oferta de centros que imparten enseñanzas de FP en dos categorías: "Centros ESO y/o Bachillerato y/o FP" y "Centros E. Primaria, ESO y Bachillerato/FP". Esto se relaciona en gran medida por la integración de las enseñanzas de Formación Profesional en los IES y no nos permite tener el dato de centros, sobre todo de titularidad privada, que sí imparten de manera exclusiva cualquiera de los títulos de FP. Teniendo en cuenta esta limitación de la información disponible, observamos que existen agrupados en estas dos categorías 6.367 centros de los cuales $4.036(63,3 \%)$ son de titularidad pública y 2.331 $(36,6 \%)$ privados.

Tabla 2: Distribución de centros educativos por Comunidad Autónoma y enseñanza ofertada. Curso 2016-2017 (ME, 2019)

\begin{tabular}{|c|c|c|c|c|c|c|c|c|}
\hline $\begin{array}{l}\text { Comunidad } \\
\text { Autónoma }\end{array}$ & $\begin{array}{l}\text { Centros } \\
\text { E. infantil }\end{array}$ & $\begin{array}{l}\text { Centros E. } \\
\text { Primaria }\end{array}$ & $\begin{array}{l}\text { Centros E. } \\
\text { Primaria y } \\
\text { ESO }\end{array}$ & $\begin{array}{c}\text { ESO y/o } \\
\text { Bachiller } \\
\text { ato y/o } \\
\text { FP }\end{array}$ & $\begin{array}{c}\text { Centros E. } \\
\text { Primaria, } \\
\text { ESO y } \\
\text { Bach./FP }\end{array}$ & $\begin{array}{l}\text { Centros } \\
\text { Específicos } \\
\text { E. Especial }\end{array}$ & $\begin{array}{l}\text { Centros } \\
\text { Específicos } \\
\text { E. Distancia }\end{array}$ & $\begin{array}{c}\text { Total } \\
\text { centros }\end{array}$ \\
\hline Andalucía & 2.182 & 1.835 & 538 & 1.039 & 204 & 58 & 5 & 5.861 \\
\hline Aragón & 336 & 298 & 60 & 143 & 35 & 16 & 0 & 888 \\
\hline Asturias & 86 & 218 & 48 & 102 & 25 & 11 & 0 & 490 \\
\hline Baleares, Is las & 144 & 225 & 65 & 89 & 28 & 8 & 0 & 559 \\
\hline Canarias & 180 & 576 & 90 & 230 & 39 & 19 & 6 & 1.140 \\
\hline Cantabria & 35 & 143 & 26 & 68 & 16 & 8 & 1 & 297 \\
\hline Castilla y León & 232 & 643 & 105 & 285 & 81 & 27 & 1 & 1.374 \\
\hline Castilla-La Manch & 445 & 658 & 69 & 270 & 31 & 22 & 0 & 1.495 \\
\hline Cataluña & 1.465 & 1.791 & 294 & 729 & 236 & 106 & 1 & 4.622 \\
\hline Com. Valenciana & 849 & 1.035 & 202 & 472 & 162 & 46 & 0 & 2.766 \\
\hline Extremadura & 242 & 411 & 35 & 157 & 23 & 19 & 0 & $\mathbf{8 8 7}$ \\
\hline Galicia & 607 & 634 & 171 & 339 & 66 & 34 & 0 & 1.851 \\
\hline Madrid & 1.467 & 841 & 177 & 454 & 350 & 66 & 4 & 3.359 \\
\hline Murcia & 147 & 386 & 74 & 138 & 41 & 12 & 0 & 798 \\
\hline Navarra & 108 & 180 & 22 & 79 & 17 & 5 & 0 & 411 \\
\hline País Vasco & 345 & 331 & 104 & 265 & 102 & 13 & 4 & 1.164 \\
\hline Rioja, La & 66 & 57 & 18 & 28 & 9 & 2 & 0 & 180 \\
\hline Ceuta & 5 & 17 & 5 & 6 & 1 & 1 & 0 & 35 \\
\hline Melilla & 10 & 14 & 1 & 7 & 1 & 1 & 0 & 34 \\
\hline & 8.951 & 10.293 & 2.104 & 4.900 & 1.467 & 474 & 22 & 28.211 \\
\hline
\end{tabular}


Así, como puede observarse en la tabla, Andalucía, Cataluña y Madrid son, junto con la Comunidad Valenciana, las comunidades en las que hay un mayor número de centros en los que se imparte algún tipo de enseñanza de Formación Profesional.

\section{Discusión y conclusiones}

A través de la revisión documental realizada es posible concluir que las recientes modificaciones realizadas en los estudios de Formación Profesional han servido para recuperar la imagen social de este tipo de enseñanzas. La FP está dejando de ser una opción marginal para aquellos estudiantes que no concluyen sus estudios de secundaria para convertirse en una opción atractiva, alternativa a los estudios universitarios, que ofrece una inserción laboral más rápida y dirigida a las ocupaciones afines con los títulos cursados, a diferencia de los estudios universitarios que, como plantean Segarra, Páramo y Puebla, "no suponen una garantía de conseguir inmediatamente un trabajo en el que los recién egresados puedan aplicar los conocimientos académicos y prácticos adquiridos a lo largo de cuatro años de formación" (2012, p.44).

Con la implantación de la LOE, los títulos se han modificado para favorecer el emprendimiento y la empleabilidad de los egresados, tratando de este modo de reducir en la medida de lo posible las altas tasas de desempleo juvenil de nuestro país. No obstante, hay que destacar la escasa incidencia en la oferta de estos títulos en la FP Dual en las distintas comunidades autónomas. Esto puede deberse a la idiosincrasia de este sector en nuestro país: la estacionalidad en el trabajo, que dificulta cualquier tipo de planificación en la organización de los recursos técnicos y humanos; la atomización del tejido empresarial compuesto principalmente por pequeñas y medianas empresas cuya supervivencia está condicionada por el éxito de un único producto/servicio; el ritmo de producción, que implica tiempos de trabajo que complican la flexibilidad horaria que requiere este sistema; $y$, en definitiva y derivado de lo anterior, las precarias condiciones económicas de una gran parte de las empresas que no se implicarían ni económica ni materialmente en el desarrollo de estas incitativas. Complicaciones todas ellas que se hace presentes también en la gestión de la Formación en Centros de Trabajo (FCT).

En este sentido, se hacen necesarias más investigaciones sobre la cuestión que, contando con datos más actualizados y específicos de cada Familia Profesional, permitan poner de relevancia la necesidad de acciones concretas que acerquen el sistema educativo a la realidad del sector profesional.

Para concluir es preciso señalar una serie de limitaciones de nuestra investigación, provenientes de la técnica de investigación elegida, el análisis documental, así como de la labor del investigador. En este sentido, los resultados de la investigación pueden estar condicionados por la selección de las fuentes de información. Del mismo modo, si bien se ha pretendido acometer este estudio desde la distancia que implica el método científico y la sistematización en el procedimiento de análisis, no podemos olvidar los posibles errores en la interpretación de los datos que se hubieran podido cometer. Por último, hay que señalar que hubiera sido deseable obtener los datos tratados directamente de las instituciones implicadas, favoreciendo así la autenticidad y actualización de la información. Este ha sido quizá uno de los problemas más importantes en tanto que no hemos tenido acceso a la información

A partir de los resultados obtenidos en esta investigación y a través de la utilización de técnicas complementarias se abren futuras líneas de trabajo que puedan ser relevantes para el campo académico y la comunidad educativa. Así, a modo de prospectiva, cabe plantearse una línea de trabajo en la que estudiar las expectativas laborales de los estudiantes de FP y compararlas con la inserción laboral de los titulados y, del mismo 


\section{modo, realizar un estudio comparativo con los titulados universitarios para analizar qué tipo de enseñanzas tienen una mejor integración en el sector profesional.}

\section{Referencias}

Bieger, C, Domingo Souto, J, Pin, JR, y García Lombardiá, P (Coords) (2018). Reflexiones sobre la Formación Profesional de Grado Medio y Superior en España. Madrid: Fundación Atresmedia, Fundación Mapfre, IESE Bussiness School.

Brunet, I y Böcker, R (2017). El modelo de la formación profesional en España. Revista Internacional de Organizaciones, 18, 89-108.

Consejo Europeo (2015). Decisión 2015/1848 de 5 de octubre relativa a la orientación de políticas de empleo de los Estados Miembros para 2015. Diario Oficial de la Unión Europea 208, 32.

Constitución Española (1978). Congreso: España.

Dulzaides Iglesias, ME y Molina Gómez, AM (2004). Análisis documental y de información: dos componentes del mismo proceso. ACIMED, 12(2), 1

Fernández San Pedro, S y González de la Fuente, A (1975). Apuntes para una historia de la Formación Profesional en España. Revista de Educación, 239(6), 81-87.

Fundación Estatal para la formación en el empleo (FUNDAE) (s.f.). Conócenos.

Gallego Ortega, JL y Rodríguez Fuentes, A (2011). La formación profesional en España: historia y actualidad. Edusk - Revista Monográfica de Educación Skepsis, 2(3), 2054-2105.

Garrido Palacios, M (2005). Historia de la educación en España (1857-1975). Una visión hasta lo local. Contraluz Asociación Cultural Cerdá y Rico. Cabra del Santo Cristo, (2), 89.

Herrero Pascual, C (1997). La investigación en análisis documental. Educación y Biblioteca, 83, 44-46.

Homs, O (2008). La formación profesional en España. Hacia la sociedad del conocimiento. Colección de Estudios Sociales, n² 25. Barcelona: Fundación La Caixa.

Infoempleo (2017). Guía de estudios superiores y de postgrado.

Ministerio de Educación y Formación Profesional (2018). Datos y cifras. Curso escolar 2018-2019. Madrid: Secretaría General Técnica, Subdirección General de Atención al Ciudadano, Documentación y Publicaciones.

Ministerio de Educación y Formación Profesional (2019). Las cifras de Educación en España. Estadísticas e indicadores. Edición 2019. Madrid: Secretaría General Técnica, Subdirección General de Atención al Ciudadano, Documentación y Publicaciones.

Ministerio de Educación, Cultura y Deporte (2017a). Panorama de la Educación. Indicadores de la OCDE 2017. Madrid: Secretaría de Estado de Educación, Formación Profesional y Universidades.

Ministerio de Educación, Cultura y Deporte (2017b). El sistema educativo español. En Estadísticas de las Enseñanzas no universitarias. Resultados detallados. Curso 2016-2017, 1-7.
Naciones Unidas (1948). Declaración Universal de los Derechos Humanos.

Organización para la Cooperación y el Desarrollo Económicos (OCDE) (2017). Panorama de la Educación 2017. Nota País.

Segarra Saavedra, J, Páramo Galdón, P y Puebla Martínez, B (2012). Jóvenes emprendedores y sus proyectos de Comunicación en la red: estudio de caso de Periodistas en potencia y Portal del Sur. AdComunica, 39-61.

Servicio Nacional de Empleo (SEPE) (2015). Sistema de Formación Profesional para el empleo en el ámbito laboral. Madrid: Servicio de Publicaciones de la Administración General del Estado.

Servicio Nacional de Empleo (SEPE) (s.f.). La formación profesional en España. Marco institucional - Oferta formativa.

Sotés-Elizalde, MA (2009). Formación profesional: sistema educativo y empresa. Educación y Educadores 2009, 12(1), 109118.

Unión Europea (2009). Carta de los Derechos Fundamentales. Charterpedia.

Unión Europea (2010). Cooperación en educación y formación profesional para apoyar la Estrategia Europa 2020. Resolución del Parlamento Europeo, de 8 de junio de 2011, sobre la cooperación en educación y formación profesional para apoyar la Estrategia Europa 2020

Valles, M (1999). Técnicas cualitativas de investigación social. Reflexión metodológica y práctica profesional. Madrid: Síntesis. 